\title{
Research in the chemistry of diterpenoid alkaloids
}

\author{
S. William Pelletier \\ Institute for Natural Products Research and Department of Chemistry, The \\ University of Georgia, Athens, Georgia 30602-2556, USA
}

\begin{abstract}
This paper summarizes some of our recent research on diterpenoid and norditerpenoid alkaloids. Structures for delatisine, vakhmatine, vakhmadine, ajabicine, tangirine, septatisine, andersobine, and deacetylheterophylloidine are discussed.
\end{abstract}

A novel furanohetisine-type alkaloid isolated from the seeds of Delphinium elatum $\mathrm{L}$. is delatisine (1). The ${ }^{13} \mathrm{C} \mathrm{nmr}$ spectrum revealed twenty carbons, none of which could be assigned to a methoxyl or $\mathrm{N}$-methyl group. These groups were also absent in the ${ }^{1} \mathrm{H} \mathrm{nmr}$ spectrum, thus suggesting that delatisine is a diterpenoid alkaloid $\left(\mathrm{C}_{20}\right)$. The molecular formula was established as $\mathrm{C}_{20} \mathrm{H}_{25} \mathrm{NO}_{3}$ by HRMS. DEPT showed: 4 quaternary carbons $(s)$ at $\delta$ $145.7,52.7,50.5,45.7 ; 10$ methines (d) at $\delta 100.2,79.6,75.7,72.2,66.3,64.4,62.0,55.4$, $50.2,50.0 ; 5$ methylenes $(t)$ at $\delta 108.2,41.6,37.3,34.3,33.9$; and 1 methyl $(q)$ at $\delta 21.9$.

Characteristic carbon and proton resonances indicated a hetisane-type exocyclic methylene group. The signal at $\delta 100.2$ indicated a carbinolamine ether. Using long-range COSY, fixed evolution HETCOR and nOe's, the structure shown below was assigned to delatisine. This structure is unusual in that there is no other diterpenoid alkaloid which contains an oxygen bridge between $\mathrm{C}-2$ and $\mathrm{C}-19$ to form a furan ring. A single crystal $\mathrm{X}$-ray diffraction analysis confirmed the structure assigned by nmr studies (1).

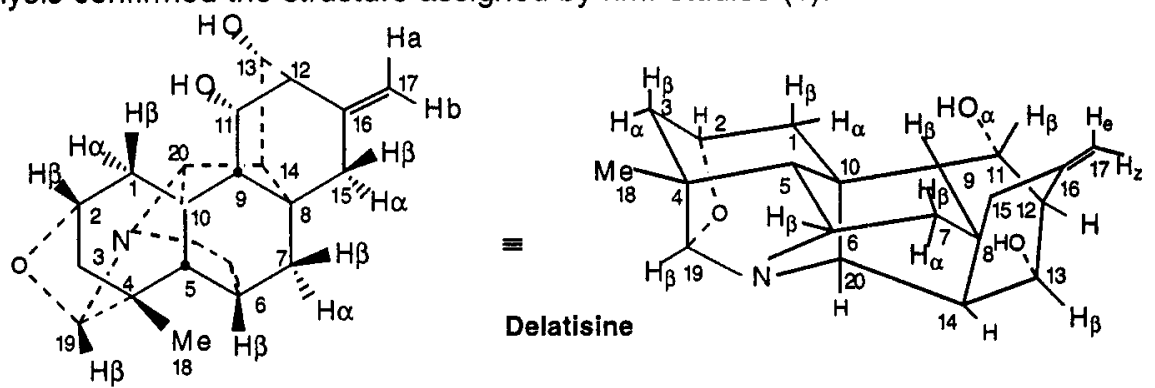

Two new water-soluble alkaloids named vakhmatine and vakhmadine have been recently isolated from Aconitum palmatum Don (2). The molecular formula for vakhmatine $\left(\mathrm{C}_{20} \mathrm{H}_{27} \mathrm{NO}_{4}\right)$ was established from the HRMS of the tetraacetate. The infra red and ${ }^{13} \mathrm{C} \mathrm{nmr}$ spectra showed the absence of carbonyl groups so one can conclude there are four hydroxyl groups in the molecule. The similarity of the ${ }^{13} \mathrm{C} \mathrm{nmr}$ spectra of vakhmatine and hetisine suggested a close relationship. The existence of a doublet at $\delta 95.5$, and the absence of a 
triplet at $\delta 65-70$, characteristic of the $19-\mathrm{CH}_{2}$ signal of $\mathrm{C}_{20}$-diterpenoid alkaloids, indicated that one of the hydroxyl groups is situated at the $C(19)$ position. The ${ }^{1} \mathrm{H}$ nmr spectrum of vakhmatine $\left(300 \mathrm{MHz}, \mathrm{CD}_{3} \mathrm{OD}\right)$ showed the following signals: $\delta 1.04\left(3 \mathrm{H}, s, 4-\mathrm{CH}_{3}\right), 1.55$ $\left(1 \mathrm{H}, d d, \mathrm{~J}_{1}=15.2, \mathrm{~J}_{2}=4.8 \mathrm{~Hz} ; 3 \beta-H\right), 1.91\left(1 \mathrm{H}, d d, \mathrm{~J}_{1}=9.0, \mathrm{~J}_{2}=2.1 \mathrm{~Hz}, 9-H\right), 1.99,2.25(1 \mathrm{H}$ each, br $d, J=17.7 \mathrm{~Hz}, 15-2 H), 2.12\left(1 \mathrm{H}, d d, J_{1}=9.3, J_{2}=1.8 \mathrm{~Hz}, 14-H\right), 2.35(1 \mathrm{H}, d, J=2.6$ $H z, 12-H), 3.00(1 H$ br $d, J=15.3 \mathrm{~Hz}, 1 \alpha-H), 3.38(1 \mathrm{H}$, br $s, 6-H), 4.02(1 \mathrm{H}$, br $m, 2 \beta-H), 4.11$ $\left(1 \mathrm{H}, d t, \mathrm{~J}_{1}=9.3, \mathrm{~J}_{2}=2.3 \mathrm{~Hz}, 13 \beta-H\right), 4.18(1 \mathrm{H}, s, 19-H), 4.22(1 \mathrm{H}, d, \mathrm{~J}=9.1 \mathrm{~Hz}, 11 \beta-H), 4.67$, 4.84 (1H each, br $s, 17-2 H)$.

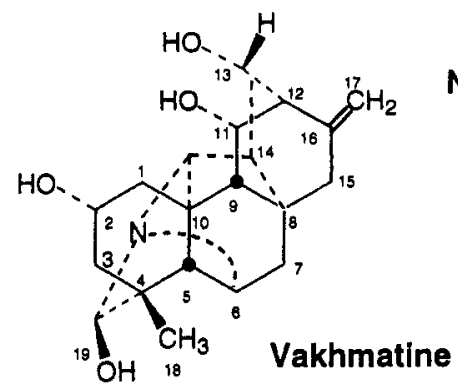

Note: Because there is substantial confusion in the literature in the manner in which the configuration of the $\mathrm{C}-13$ hydoxyl in hetisine derivatives is represented [both $\alpha$ and $\beta]$, the convention used in this paper is defined as follows: the boat containing both $\mathrm{C}-11$ and $\mathrm{C}-13$ and formed by carbon atoms $8,9,11,12,13$, and 14 is selected as the reference ring. The hydroxyls at $\mathrm{C}-11$ and $\mathrm{C}-13$ are then both $\alpha$.

Examination of the 2D-COSY spectrum of the tetraacetate permitted three acetoxy groups to be assigned to $\mathrm{C}-2 \alpha, \mathrm{C}-11 \alpha$, and $\mathrm{C}-13 \alpha$. The site of the remaining acetoxyl group at $C-19$ was established by a down-field singlet at $\delta 5.73$ and a doublet at $\delta 92.6$. Analysis of 2D-HETCOR and 2D-COSY spectra and nOe experiments established the structure of vakhmatine as shown (2).

Vakhmadine was isolated as a quaternary base. The absence of a carbonyl group in the ir (Nujol) and ${ }^{13} \mathrm{C} \mathrm{nmr}\left(\mathrm{D}_{2} \mathrm{O}\right)$ spectra demonstrated that the $\mathrm{C}-6$ keto group was masked in both crystalline form and solution, although its HRMS spectrum gave $\mathrm{m} / \mathrm{z} 359.2091$ (calcd 359.2097), indicative of a free base $\left(\mathrm{C}_{21} \mathrm{H}_{29} \mathrm{NO}_{4}\right)$ with a carbonyl group at $\mathrm{C}(6)$. The existence of such a quaternary- $N$ center in the molecule was apparent by its deshielding effects on $\mathrm{N}$-Me ( $\delta 2.58), \mathrm{H}-19(1 \mathrm{H}$ each, $\delta 2.97,4.05, d, \mathrm{~J}=11.7 \mathrm{~Hz})$ and $\mathrm{H}-20(\delta 4.22, s)$ compared with the values of hetidine-type alkaloids, and also by the presence of a C- 6 singlet at $\delta 105.0$ and a $\gamma$ effect of $6-\mathrm{OH}$ causing an up-field shift on $\mathrm{N}-\mathrm{Me}(\delta 36.6 \mathrm{ppm})$. Signals were observed at: ${ }^{1} \mathrm{H} \mathrm{nmr}\left(250 \mathrm{MHz}, \mathrm{D}_{2} \mathrm{O}\right): \delta 1.40\left(3 \mathrm{H}, s, 4-\mathrm{CH}_{3}\right), 2.58\left(3 \mathrm{H}, \mathrm{s}, \mathrm{N}-\mathrm{CH}_{3}\right), 2.97,4.05(1 \mathrm{H}$ each, $d$, $J=11.7 \mathrm{~Hz}, 19-2 H), 3.33(1 \mathrm{H}, d, J=4.3 \mathrm{~Hz}, 3 \beta-H), 3.93\left(1 \mathrm{H}, d, J=11.0 \mathrm{H}_{2}, 13 \beta-H\right), 3.97(1 \mathrm{H}$, br $m, 2 \beta-H), 4.22(1 \mathrm{H}, s, 20-H), 4.59,4.73(1 \mathrm{H}$ each, $s, 17-H)$.

Acetylation of vakhmadine with $\mathrm{Ac}_{2} \mathrm{O} / \mathrm{C}_{5} \mathrm{H}_{5} \mathrm{~N}$ in the presence of DMAP at $60^{\circ}$, followed by chromatographic purification, gave a triacetyl derivative, $\mathrm{C}_{27} \mathrm{H}_{35} \mathrm{NO}_{7},[\mathrm{M}]+485, \mathrm{mp}$. $261.0-262.0^{\circ}$. The presence of a keto group $\left(\delta 202.4\right.$, ir $\left.1695 \mathrm{~cm}^{-1}\right)$, and three acetyl groups $(\delta 170.2,169.4,169.8)$, indicates that the masked $C-6$ keto group in vakhamadine was restored by the acetylation. This derivative showed structural features of hetidine-like alkaloids, i.e., the existence of an $N$-Me $(\delta 2.22, \delta 43.2)$, an exocyclic methylene $(\delta 4.68,4.84, \delta 146.6$, 107.0), and the C- 6 ketone mentioned above. The 2D COSY spectrum exhibited a strong coupling of two down-field vicinal protons at $\delta 4.63\left(d, \mathrm{~J}=4.6 \mathrm{~Hz}\right.$ ) and $5.44\left(d d d, \mathrm{~J}_{1}=\mathrm{J}_{2}=\right.$ $4.6, J_{3}=2.1 \mathrm{~Hz}$ ), which were reasonably placed in ring $A$ for such a skeleton. The doublet, which showed an nOe enhancement to the 4-Me $(\delta 1.48)$, was assigned to $\mathrm{H}-3 \beta$, and consequently the other one at $\delta 5.44$ should be $\mathrm{H}-2 \beta$ according to its coupling pattern. Two of the 


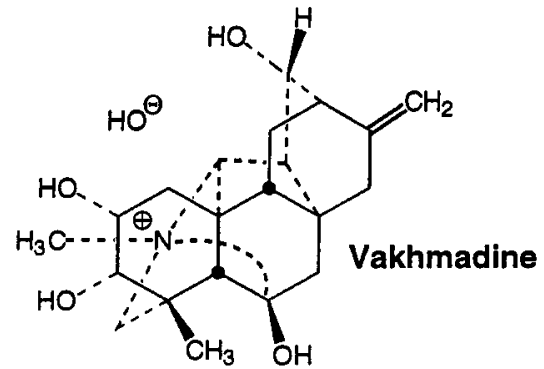

three acetyl groups were assigned to the C-2 $\alpha$ and $\mathrm{C}-3 \alpha$ positions. The existence of a downfield signal at $\delta 4.97\left(d t, J_{1}=9.6, J_{2}=1.8 \mathrm{~Hz}\right)$ allowed the third acetyl group to be placed at the $\mathrm{C}-13 \alpha$ position because this signal was strongly coupled with the vicinal $\mathrm{H}-14$ at $\delta 2.43$ ( $d d, \mathrm{~J}_{1}=9.6, \mathrm{~J}_{2}=2.5 \mathrm{~Hz}$ ), as shown in the 2D COSY spectrum, while the latter was characterized by its nOe enhancement to the $\mathrm{H}-20(\delta 2.80, s)$.

From the seeds of Consolida ambigua (L.) P.W. Ball \& Heyw [syn. Delphinium ajacis L.] several norditerpenoid alkaloids have been isolated: thirteen from the stem, six from the leaves and eight from the roots. A novel diterpenoid alkaloid, ajabicine, has been isolated from the leaves ( 3 ). The amorphous compound was obtained in $0.0012 \%$ yield by acid-base extraction procedure $(\mathrm{pH} 8)$ and chromatography on $\mathrm{Al}_{2} \mathrm{O}_{3}$ by vlc and the Chromatotron. Ajabicine, $\mathrm{C}_{22} \mathrm{H}_{33} \mathrm{NO}_{2}\left(\mathrm{M}^{+} \mathrm{m} / \mathrm{z} 343\right)$, showed in the ${ }^{13} \mathrm{C} \mathrm{nmr}$ spectrum 22 resonances comprised of one $\mathrm{sp}^{2}$ singlet $(\delta$ 156.6) which is assigned to the carbon containing an exocyclic methylene, three $\mathrm{sp}^{3}$ singlets $(\delta 33.3,49.8,80.8)$, seven $\mathrm{sp}^{3}$ doublets, $(\delta 38.8,46.7,47.1$, $48.5,51.8,62.8,73.3)$, nine methylenes $(\delta 26.3,30.8,32.7,33.3,33.5,35.8,48.6,60.2,103.2)$ and two methyl carbons $(\delta 13.3,27.5)$. The ${ }^{1} \mathrm{H}$ nmr spectrum featured signals at $\delta 4.89,5.00$ (each $\left.1 \mathrm{H}, s,>\mathrm{C}=\mathrm{CH}_{2}\right), 3.96[1 \mathrm{H}, t, \mathrm{CH}(\mathrm{OH})], 1.03\left(3 \mathrm{H}, t, \mathrm{CH}_{2} \mathrm{CH}_{3}\right), 0.80\left(3 \mathrm{H}, s\right.$, tert- $\left.\mathrm{CH}_{3}\right)$. The molecular formula and the presence of an $\mathrm{N}$-ethyl group indicated that ajabicine is a diterpenoid and not a norditerpenoid alkaloid. This conclusion was supported by the absence of signals for methoxyl groups in the proton and carbon-13 nmr spectra, which are normally present in norditerpenoid alkaloids.

The usual diterpenoid ring systems cannot accommodate the quaternary carbon signal of ajabicine at $\delta 80.0$ bearing a hydroxyl group. To account for this carbon signal, the C-8-C9 or the $\mathrm{C}-8-\mathrm{C}-14$ bond must be cleaved, to form a rearranged skeleton.

The results of COSY, TOCSY, HETCOR, and COLOC experiments (in $\mathrm{CDCl}_{3}$ ) clearly established the presence of partial structural moieties in ajabicine. Connectivities of the remaining three quaternary centers, one methine, two methylenes and one methyl group were established by COSY, selective INEPT and FLOCK experiments and all these data are satisfactorily explained by the structure shown (3).

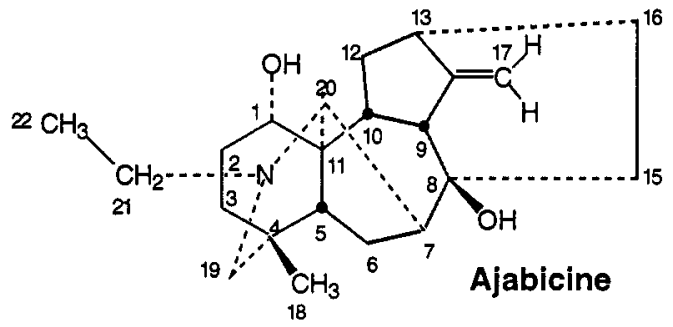

A dimeric diterpenoid alkaloid, tangirine (4), was isolated in $0.001 \%$ yield from the neutral $\mathrm{CHCl}_{3}$ fraction obtained during the isolation of tangutisine by chromatography over $\mathrm{Al}_{2} \mathrm{O}_{3}$. The molecular formula of tangirine was established as $\mathrm{C}_{49} \mathrm{H}_{62} \mathrm{~N}_{2} \mathrm{O}_{7}$ by HRFAB-MS (m/z 790.4558, cal. 790.4557). Sixty-one protons and 49 carbons were visible in the ${ }^{1} \mathrm{H}$ and ${ }^{13} \mathrm{C} \mathrm{nmr}$ spectra in $\mathrm{CDCl}_{3}$ and all one-bond ${ }^{1} \mathrm{H}-13 \mathrm{C}$ connectivities were established by a HETCOR experiment. The DEPT spectrum indicated 11 quaternary carbons $(s), 19$ methines (d), 15 methylenes $(t)$ and 4 methyls $(q)$. Of these, seven carbon singlets, eleven doublets, seven triplets, and three 
quartets appeared to belong to 6-benzoylheteratisine. The up-field shifts of C-7- and C-15by $\sim 4.5 \mathrm{ppm}$ when compared with the values in 6-benzoylheteratisine can be attributed to the bulky substituent group attached at the $\mathrm{C}-8$ position. The ${ }^{1} \mathrm{H}-{ }^{1} \mathrm{H}$ COSY, the NOESY, and the $\mathrm{HMBC}$ spectral results allowed the derivation of a partial structure for tangirine. The mass spectral fragmentations support the presence of a methoxyl group at $C(1)$ and a benzoate ester group in 6-benzoylheteratisine.
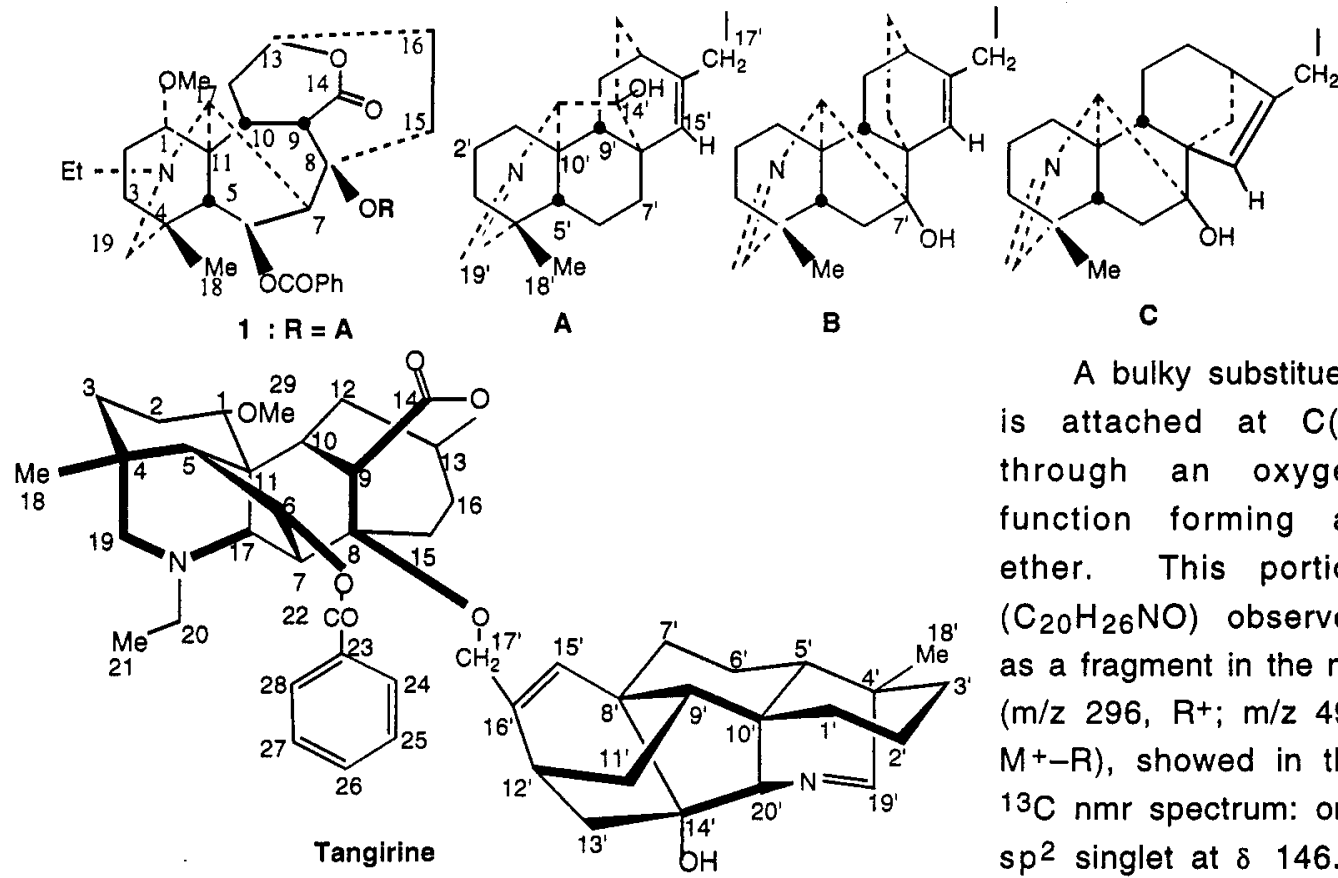

A bulky substituent is attached at $C(8)$ through an oxygen function forming an ether. This portion $\left(\mathrm{C}_{20} \mathrm{H}_{26} \mathrm{NO}\right)$ observed as a fragment in the $\mathrm{ms}$ $\left(\mathrm{m} / \mathrm{z} 296, \mathrm{R}^{+} ; \mathrm{m} / \mathrm{z} 494\right.$ $\left.M^{+}-R\right)$, showed in the ${ }^{13} \mathrm{C} \mathrm{nmr}$ spectrum: one $s p^{2}$ singlet at $\delta 146.0$, four sp $\mathrm{sp}^{3}$ singlets at $\delta 72.5,45.0,44.9,43.1$, two $\mathrm{sp}^{2}$ doublets at $\delta 169.2,127.8$, four $\mathrm{sp}^{3}$ doublets at $\delta 80.3,46.4,44.3,31.5$, eight methylenes at $\delta 60.4,42.8,31.5,30.6,30.5,28.4$, 27.4, 20.6 and one methyl at $\delta 19.0$. The ${ }^{1} \mathrm{H}$ nmr signal at $\delta 3.82(2 \mathrm{H}, d d, A B, \mathrm{~J}=12.0 \mathrm{~Hz}$; $\left.{ }^{13} \mathrm{C}, 60.4 \mathrm{ppm}\right)$, showing a connection (COSY, nOe) with $\delta 4.98\left(1 \mathrm{H}, \mathrm{br} s ;{ }^{13} \mathrm{C}, \delta 127.8 \mathrm{ppm}\right)$ suggested the presence of the grouping, $-\mathrm{CH}=\mathrm{C}-\mathrm{CH}_{2}-\mathrm{O}-$. Also the signal at $\delta 7.32(1 \mathrm{H}$, $\left.d, \mathrm{~J}=2.5 \mathrm{~Hz} ;{ }^{13} \mathrm{C}, \delta 169.2 \mathrm{ppm}\right)$ was coupled (COSY) to $\delta 3.30\left(1 \mathrm{H}, \mathrm{br} \mathrm{s} ;{ }^{13} \mathrm{C}, 80.3 \mathrm{ppm}\right)$ indicative of the system $-\mathrm{C}-\mathrm{CH}=\mathrm{N}-\mathrm{CH}$. The three-proton singlet at $\delta 1.00\left({ }^{13} \mathrm{C}, 19.0 \mathrm{ppm}\right)$ suggested the presence of a tertiary methyl group. The molecular formula, $\mathrm{C}_{20} \mathrm{H}_{26} \mathrm{NO}$, and the functional groups described, suggested one of three possible diterpenoid structures (A, B or C). Extensive 2-D nmr experiments finally led to the structure shown. Tangirine is the only example of a dimeric alkaloid in which a norditerpenoid and a diterpenoid alkaloid are joined together (4).

A new atisane-type diterpenoid alkaloid, septatisine (5), has been isolated from Aconitum septentrionale. The molecular formula, $\mathrm{C}_{22} \mathrm{H}_{31} \mathrm{NO}_{3}$, established by HRMS, requires eight units of unsaturation, one of which was accounted for by a terminal, and presumably exocyclic, methylene unit as indicated by the ${ }^{1} \mathrm{H}$ and ${ }^{13} \mathrm{C} \mathrm{nmr}$ spectra: $\delta 4.94(d d, \mathrm{~J}=$ 2.6, $1.2 \mathrm{~Hz}) ; 4.83(d d, J=2.1,1.2(\mathrm{~Hz}) ; \delta 157.9(\mathrm{~s}), 103.8(\mathrm{t})$. These results indicated that septatisine is a $\mathrm{C}_{20}$-diterpenoid alkaloid with two additional carbons and the remaining seven units of unsaturation elaborated by a polycyclic system. The appearance of an isolated dimethylene proton-coupled spin system in the homonuclear COSY spectrum ( $\delta 3.78$ 
( $d d d, \mathrm{~J}=13.6,12.1,6.9 \mathrm{~Hz}), 3.56(d d d, \mathrm{~J}=13.6,8.6,2.2 \mathrm{~Hz}$ ), 3.03 ( $d d d, \mathrm{~J}=12.4,12.1,8.6$ $\mathrm{Hz}$ ), $2.81(d d d, \mathrm{~J}=12.4,6.9,2.2 \mathrm{~Hz})$ ) with the corresponding carbons located by a heteronuclear COSY (fixed evolution HETCOR) spectrum $(\delta 61.7,51.5)$, indicated that these two "additional" carbons were attached to the nitrogen in the form of an ethanolamino grouping.

Of the three most likely diterpene alkaloidal skeleta (atisane, veatchine and hetisane types), the atisane structure with one additional unit of unsaturation (C14/C20 bridge) was confirmed by spectroscopic methods (5).

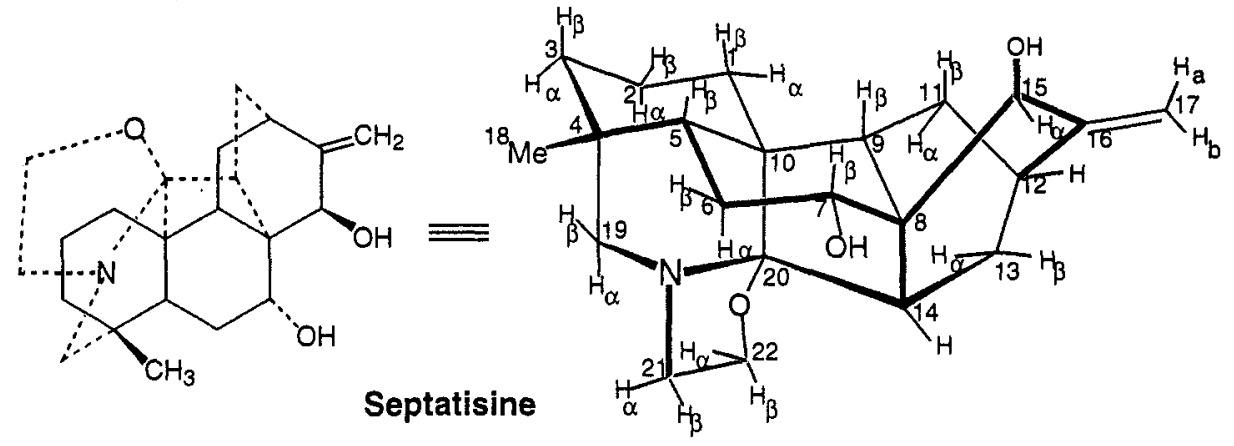

In the course of our studies on the minor constituents of Delphinium andersonii, we isolated by droplet counter current chromatographic separation, a new diterpenoid alkaloid designated as andersobine (6), and determined its structure by detailed $\mathrm{nmr}$ spectral studies.

The molecular formula, $\mathrm{C}_{22} \mathrm{H}_{29} \mathrm{NO}_{4}$, for andersobine was established by HRMS. Andersobine, $\mathrm{mp} 310^{\circ} \mathrm{C}$, is very sparingly soluble in $\mathrm{CDCl}_{3}$; its ${ }^{1} \mathrm{H}$ and ${ }^{13} \mathrm{C} \mathrm{nmr}$ spectra were determined in $C D_{3} S_{O C D}$ and $C_{5} D_{5} N$. The ${ }^{1} \mathrm{H}$ nmr spectrum in $C_{3} S_{3} O C D_{3}$ indicated the presence of a tertiary methyl at $\delta 0.95(3 \mathrm{H}, s)$ and an acetate methyl at $\delta 2.02(3 \mathrm{H}, s)$. The downfield part of the spectrum showed the presence of an exocyclic methylene group at $\delta$ $4.92,4.83($ each $1 \mathrm{H})$. These inferences were supported by the characteristic carbon resonances in the ${ }^{13} \mathrm{C} \mathrm{nmr} \mathrm{spectrum} \mathrm{at} \delta 19.1$ (tert- $\left.\mathrm{CH} 3\right), \delta 170.5\left(\mathrm{OCOCH}_{3}\right), \delta 20.8\left(\mathrm{OCOCH}_{3}\right), \delta$ $151.7(s)$ and $\delta 109.9(t)\left(=\mathrm{CH}_{2}\right)$ groups. An acetate accounts for two carbons and andersobine should therefore be an acetate of an alkaloid having the formula $\mathrm{C}_{20} \mathrm{H}_{27} \mathrm{NO}_{3}$. The absence of methoxyl, $\mathrm{N}$-methyl or $\mathrm{N}$-ethyl groups suggested that andersobine is a diterpenoid and not a norditerpenoid alkaloid. Of the various skeleta known for the diterpenoid alkaloids, andersobine must possess the hetisane skeleton since all the other skeleta have to be $\mathrm{N}$-alkyl derivatives. Andersobine possesses one acetoxyl and two hydroxyl groups. The ${ }^{13} \mathrm{C} \mathrm{nmr}$ spectrum (DMSO- $d_{6}$ ) shows 22 signals for all the carbon atoms of the molecule. An APT/DEPT spectrum revealed the expected five nonprotonated carbon singlets at $\delta 170.5$, $151.7,48.5$ (two carbons; these appeared as separate signals at $\delta 50.1,49.4$ in py- $d_{5}$ ), 44.0, nine methine doublets at $\delta 87.6,73.0,71.8,69.9,61.7,60.6,43.5,42.9,33.0$, six methylene triplets at $\delta 109.9,32.5,31.8,28.0,26.2,25.6$ and two methyl quartets at $\delta 20.8$ and 19.1.

On the basis of extensive $\mathrm{nmr}$ data, andersobine was assumed to bear hydroxyl groups at $\mathrm{C}-3, \mathrm{C}-15$ and $\mathrm{C}-19$, with one of these being an acetate group. Two separate attempts to solve the structure of andersobine by $X$-ray crystallography were unsuccessful in spite of the availability of suitable crystals. An X-ray crystallographic analysis of the 4-dimethylaminobenzoate ester of andersobine also failed. Finally, the structure of andersobine was established by ${ }^{1} \mathrm{H}$ CosY, one dimensional ( $1 \mathrm{D}$; in $\mathrm{C}_{5} \mathrm{D}_{5} \mathrm{~N}$ ), two dimensional (2D; in $\mathrm{C}_{5} \mathrm{D}_{5} \mathrm{~N}$ and $\mathrm{CD}_{3} \mathrm{SOCD}_{3}$ ), nOe studies, and selective INEPT experiments (6). 


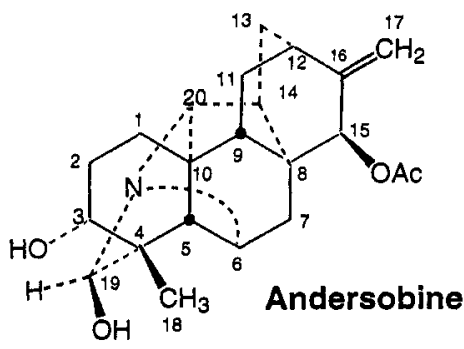

From Delphinium albiflorum (DC.), a plant native to eastern Turkey, a new alkaloid (1), $\mathrm{mp}$. $160-162^{\circ} \mathrm{C} ;[\alpha] \mathrm{D}-59.9^{\circ}$, has been isolated (7). The molecular formula, $\mathrm{C}_{21} \mathrm{H}_{27} \mathrm{NO}_{3}$, was derived from the HRMS and ${ }^{13} \mathrm{C} \mathrm{nmr}$ data. The compound exhibited a characteristic proton $\mathrm{nmr}$ spectrum for the presence of an exocyclic methylene $(\delta 4.94,4.76$, each $1 \mathrm{H})$, a tertiary-Me $(\delta 1.08,3 \mathrm{H})$, an $\mathrm{N}-\mathrm{Me}(\delta 1.45$,

$3 \mathrm{H})$, and the absence of $\mathrm{OMe}$ groups. These data indicated that this is a diterpenoid alkaloid. The ${ }^{13} \mathrm{C} \mathrm{nmr}$ spectrum and DEPT experiments in $\mathrm{CDCl}_{3}$ indicated the presence of two methyls at $\delta 27.2,41.9$; seven methylenes at $\delta 109.9,57.5,52.3,48.3,40.7,36.2,23.4$; six methines at $\delta 67.1,64.5,59.9,56.6,53.5,46.4$; and six quaternary carbons at $\delta 210.5,209.0$ (weak), 142.7, 45.0,40.9, 37.1. The weak signal at $\delta 209.0$ was observed at $\delta 206.6$ when the spectrum was recorded in $\mathrm{C}_{6} \mathrm{D}_{6}$.

The molecular formula, $\mathrm{C}_{21} \mathrm{H}_{27} \mathrm{NO}_{3}$, indicates nine degrees of unsaturation of which three are accounted for by the presence of two carbonyls ( $\delta 210.5$ and 209.0) and the exocyclic methylene ( $\delta 142.6$ and 109.9 ). The remaining six degrees of unsaturation indicate the presence of a hexacyclic skeleton as in the atisane-type alkaloids. The C-16 carbon signal at $\delta 142.7$ indicates that there is no $\mathrm{OH}$ group at $\mathrm{C}-15$, as an $\mathrm{OH}$ at $\mathrm{C}-15$ would have caused the $\mathrm{C}-16$ signal to shift down field by $\sim 10 \mathrm{ppm}$ as in atisine. The signals at $\delta 67.1$ and $\delta 64.5$ were assigned to $\mathrm{C}-20$ and $\mathrm{C}-2$, respectively, based on the COSY spectrum which showed a correlation of $\mathrm{H}-2(\delta 3.92)$ with $\mathrm{H}-1$ and $\mathrm{H}-3 ; \mathrm{H}-20(\delta 3.20)$ showed a correlation with $\mathrm{H}-14$ ( $\delta$ 2.60). In the HETCOR spectrum, the methine signals at $\delta 67.1$ and $\delta 64.5$ showed correlations with $\mathrm{H}-20(\delta 3.20)$ and $\mathrm{H}-2(\delta 3.92)$, respectively. Comparison of the ${ }^{1} \mathrm{H}$ and ${ }^{13} \mathrm{C} \mathrm{nmr}$ spectral data of 1 with those of the known compounds, suggested that the alkaloid may be identical with deacety/heterophylloidine which had been prepared by alkaline hydrolysis of heterophylloidine (4). Deacetylheterophylloidine has not been reported as a natural product. Comparison of the tlc, mixture $\mathrm{mp}$, and ir spectra confirmed the identity of the alkaloid isolated from $D$. albiflorum with deacetylheterophylloidine (7).

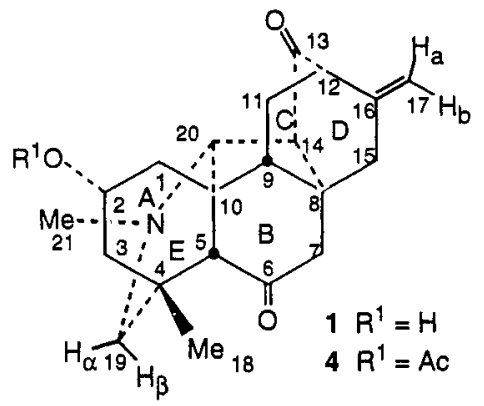

References

1. S. A. Ross, B. S. Joshi, H. K. Desai, S. W. Pelletier, M. G. Newton, X. Zhang and J. K. Snyder, Tetrahedron, 47, 9585-9598 (1991).

2. Q. Jiang and S. W. Pelletier, J. Nat. Prod., 54, 525531 (1991).

3. B. S. Joshi, M. S. Puar, H. K. Desai, S. A. Ross, J. Lu, and S. W. Pelletier, Tetrahedron Letters, 34, 14411444 (1993).

4. B. S. Joshi, Y. Bai, D. H. Chen, and S. W. Pelletier, Tetrahedron Letters, 34, 7525-7528 (1993).

5. B. S. Joshi, H. M. Sayed, S. A. Ross, H. K. Desai, S. W. Pelletier, P. Cai, J. K. Snyder, and A. J. Aasen, Can. J. Chem., 72, 100-104 (1994).

6. B. S. Joshi, M. S. Puar, Y. Bai, A. M. Panu, and S. W. Pelletier, Tetrahedron, 50, 1228312292 (1994).

7. A. Ulubelen, H. K. Desai, B. S. Joshi, V. Vobalaboina, S. W. Pelletier, A. H. Meriçle, F. Meriçli and H. Özçelik, J. Nat. Prod., in press (1995). 